\title{
New structural units in molybdenum oxyfluoride chemistry
}

David W. Aldous and Philip Lightfoot*

School of Chemistry and EaStChem, University of St Andrews, St Andrews, Fife, KY16 9ST, UK.

E-mail: pl@st-and.ac.uk

\begin{abstract}
The solvothermal syntheses and crystal structures of five new molybdenum oxyfluorides are presented. These exhibit three novel structural units, each containing Mo in a reduced oxidation state: a dimeric $\left[\mathrm{Mo}_{2} \mathrm{O}_{4} \mathrm{~F}_{2}\left(\mathrm{C}_{2} \mathrm{H}_{8} \mathrm{~N}_{2}\right)_{2}\right]$ unit $\left(\mathrm{Mo}^{4+}\right)$, a tetrameric $\left[\mathrm{Mo}_{4} \mathrm{O}_{8} \mathrm{~F}_{10}\right]^{6-}$ unit $\left(\mathrm{Mo}^{5+}\right)$ and an infinite chain $\left[\mathrm{MoOF}_{3}\right]_{\mathrm{n}}^{-}$unit $\left(\mathrm{Mo}^{4+}\right)$. Mo-Mo bonding is observed in each of the new building units.
\end{abstract}

\section{Keywords}

Molybdenum oxyfluoride; solvothermal synthesis; metal-metal bonding; crystal structure

\section{Highlights}

- A facile route to novel reduced molybdenum oxyfluorides

- New dimer and tetramer units containing Mo-Mo bonds

- First example of a reduced, infinitely extended molybdenum oxyfluoride

\section{Introduction}

The synthetic and structural chemistry of metal oxyfluorides (more precisely 'oxide fluorides') is relatively under-developed compared to the corresponding oxide chemistry ${ }^{1}$. Recently we have greatly expanded the chemistry of vanadium oxyfluorides, in particular using solvothermal methods, and this has led to a reasonably well-developed understanding of the factors that dictate their compositional and structural features ${ }^{2-7}$. In the case of molybdenum oxyfluorides (MoOFs) both solid-state and solution-based methods have been used in the past to prepare a select number of examples of MoOFs containing a variety of structural building units. A summary of the major structural elements that are known for relatively fluorine-rich compositions (ie. $\mathrm{O} / \mathrm{F} \leq 3 / 1$ ) is presented in Table 1 . We note that the majority of these examples are purely inorganic, though there are a couple of 'hybrid' cases. In addition, there are further examples of 'fluorinated polyoxomolybdates', which have typically higher $\mathrm{O} / \mathrm{F} \operatorname{ratios}^{21,22}$. We have now begun to explore the solvothermal chemistry of molybdenum in fluorine-rich environments, and here we report some of our preliminary results, in which we isolate three novel structural/compositional building units, each containing Mo in a partially reduced oxidation state.

\section{Experimental}

2.1 Materials and Methods: All chemicals were purchased from commercial sources and used without further purification. Phase purity of the reaction products was established by comparison of powder X-ray diffraction patterns simulated on the basis of the observed 
crystal structures to those measured experimentally on a Stoe STADI/P powder diffractometer, using $\mathrm{CuK} \alpha_{1}$ radiation. In addition, $\mathrm{CHN}$ analysis was carried out (Table 2)

2.2 General Synthesis: Our syntheses are typically carried out in a systematic manner, starting from a simple reaction composition comprising a molybdenum source $\left(\mathrm{MoO}_{3}\right)$, hydrofluoric acid (HF, 48\% aq.), a mixed water/ethylene glycol (EG) solvent, and an added 'template', which may be either an inorganic salt or an organic amine. These are mixed and heated together in a sealed Teflon-lined autoclave for 24 hours. Within each compositional system, variations are made to (i) the water / ethylene glycol ratio (ii) the $\mathrm{MoO}_{3} /$ template ratio and (iii) the temperature.

For the five reaction products described herein, the specific details of the reactions used to prepare single crystals are given in Table 2.

2.3 X-ray Crystallography: Single crystals were analysed using a Rigaku Mercury CCD equipped with graphite monochromated $\mathrm{MoK}_{\alpha}$ radiation. Intensity data were collected by the narrow frame method at $93 \mathrm{~K}$ and corrected for Lorentz and polarisation effects as well as absorption by Multi-Scan techniques. All structures were solved by direct methods and refined by full-matrix least-squares cycles in SHELX-97 $7^{23}$. All non-H atoms were refined with anisotropic thermal parameters; $\mathrm{H}$ atoms in 1, 2 and $\mathbf{5}$ were treated as 'riding'. Hydrogen atoms on the $\mathrm{NH}_{4}{ }^{+}$ions in $\mathbf{3}$ were not located.Correct assignments of $\mathrm{O} / \mathrm{F}$ atoms were confirmed by bond-valence sum (BVS) analysis ${ }^{24,25}$. Crystallographic details are provided in Table 3, with selected bond distances in Table 4. Full crystallographic details (cif format) have been deposited*.

\section{Results}

\subsection{Description of the crystal structures}

3.1.1 $\left[\mathbf{C}_{2} \mathbf{H}_{10} \mathbf{N}_{2}\right]_{2}\left[\mathrm{Mo}_{2} \mathbf{O}_{5} \mathbf{F}_{6}\right]$ (1) exhibits the corner-shared octahedral dimer unit $\left[\mathrm{Mo}_{2} \mathrm{O}_{5} \mathrm{~F}_{6}\right]^{4-}$ previously observed in $\mathrm{Ba}_{4}\left[\mathrm{Mo}_{2} \mathrm{O}_{5} \mathrm{~F}_{6}\right] \mathrm{F}\left(\mathrm{HF}_{2}\right)_{3} \times \mathrm{XH}_{2} \mathrm{O}$ (ref. 15). The structure has one crystallographically-distinct $\mathrm{Mo}$ site, which is confirmed as $\mathrm{Mo}^{6+}$ by BVS calculations. The dimer may be regarded as composed from two $f a c-\mathrm{MoO}_{3} \mathrm{~F}_{3}$ octahedra fused through a common $\mathrm{O}$ atom (Figure 1). These dimers are interconnected through a hydrogen-bond network via the ethylenediammonium cations. The geometry within the dimer is very similar to that observed in the previously reported example ${ }^{15}$, and the details of this structure are reported here mainly as a comparison to compound $\mathbf{2}$.

3.1.2 $\left[\mathrm{Mo}_{2} \mathrm{O}_{4} \mathrm{~F}_{2}\left(\mathrm{C}_{2} \mathrm{H}_{8} \mathrm{~N}_{2}\right)_{2}\right] \cdot \mathrm{C}_{2} \mathrm{H}_{6} \mathrm{O}_{2}$ (2) is an unusual compound incorporating a neutral octahedral dimer (Figure 2) in which two symmetry-equivalent octahedral Mo centres are coordinated by bridging oxide ligands, terminal O/F ligands (disordered) and bidentate ethylenediammine ligands. A molecule of solvent is also incorporated. Elemental analysis supports the assignment of this guest as a neutral ethylene glycol molecule, rather than an ethylenediammine molecule or its protonated cation. The resultant assignment of the 50:50 $\mathrm{O} / \mathrm{F}$ occupancy of the terminal sites is required by the BVS analysis, which confirms the Mo oxidation state to be +5 (also in agreement with the short Mo-Mo distance suggesting Mo-Mo bonding).

3.1.3 $\left(\mathrm{NH}_{4}\right)_{6}\left[\mathrm{Mo}_{4} \mathrm{O}_{8} \mathrm{~F}_{10}\right](3)$ and $\mathrm{K}_{6}\left[\mathrm{Mo}_{4} \mathrm{O}_{8} \mathrm{~F}_{10}\right]$ (4) are isostructural compounds based on a novel tetrameric unit (Figure 3(a)). Bonds to the bridging versus terminal $\mathrm{O}$ and $\mathrm{F}$ atoms 
follow the expected trends in bond-length/strength and confirm the oxidation states of the two independent Mo sites as +5 . This is again in agreement with the observation of a short inter-octahedral Mo-Mo contact through the shared $\mathrm{O}(3) / \mathrm{O}(3)$ ' edge. The tetrameric anionic units pack in a 'herring-bone' fashion (Figure 3(b)) into layers in the $b c$ plane which then stack along $a$, interspersed by the counter-cations (Figure 3(c)).

3.1.4 $\left[\mathbf{C}_{4} \mathbf{H}_{12} \mathbf{N}_{2}\right]_{0.5}\left[\mathrm{MoOF}_{3}\right](5)$ adopts a novel infinite zig-zag chain structure (Figure 4(a)). The building unit (Figure 4(b)) consists of a single octahedral $\mathrm{Mo}^{4+}$ centre coordinated by four bridging $\mathrm{F}$ atoms and single, terminal $\mathrm{F}$ and $\mathrm{O}$ atoms. The resulting chains are aligned along the $c$-direction and are separated from neighbouring chains along $a$ by the protonated piperazinium template (Figure 4(c)). Within each chain there is a distinct alternation of 'long-short' Mo-F bond lengths and corresponding Mo-Mo interoctahedral contacts, once again indicative of Mo-Mo bonding.

\section{Discussion and Conclusions}

The dimeric unit in compound $\mathbf{1}$ has been previously observed, but the other compounds exhibit novel structural units. Compound 2 exhibits only the second example of the coordination of an $\mathrm{N}$-donor ligand in a MoOF. Compounds $\mathbf{3}$ and $\mathbf{4}$ introduce the first example of a highly fluorinated tetrameric unit in MoOF chemistry. The $\left[\mathrm{Mo}_{4} \mathrm{O}_{8} \mathrm{~F}_{10}\right]^{4-}$ unit is topologically analogous to the $\left[\mathrm{V}_{4} \mathrm{O}_{4} \mathrm{~F}_{14}\right]^{6-}$ unit we have previously observed ${ }^{2}$; the higher $\mathrm{O} / \mathrm{F}$ ratio in the present case is accommodated by each Mo atom having three oxide ligands, in both terminal and bridging modes, rather than just the terminal $\mathrm{V}=\mathrm{O}$ group and bridging $\mathrm{F}$ ligands in the VOF analogue. We are aware of two previously known examples of tetrameric MoOF units (not listed in Table 1); these both contain Mo(VI) and have much lower F/O ratios. The $\left[\mathrm{Mo}_{4} \mathrm{O}_{12} \mathrm{~F}_{2}\right]^{2-}$ unit has two octahedral Mo centres bridged through a fluoride 'edge' and capped by two tetrahedral $\mathrm{MoO}_{4}$ groups ${ }^{26}$. The $\left[\mathrm{Mo}_{4} \mathrm{O}_{12} \mathrm{~F}_{3}\right]^{3-}$ unit has two edge-sharing octahedral dimers further fused via a four-coordinate $\mathrm{F}^{-}$ligand ${ }^{27}$. The previously known MoOF chain structures each incorporate Mo in the +VI oxidation state. Compound 5 represents the first example of an infinite connectivity MoOF with Mo in a reduced state. The edge-sharing chain seen in $\mathrm{NaMoO}_{3} \mathrm{~F}^{18}$ is the most closely related to that observed in $\mathbf{5}$, however it differs in the relative orientation of the shared edges along the chain, in addition to the oxidation state of the Mo and the O/F ratio. In $\mathrm{NaMoO}_{3} \mathrm{~F}$ cisedges are shared, through a common three-coordinated $\mathrm{O}$ atom, resulting in a planar zigzag conformation (Figure 4a). In $\mathbf{5}$ the edges shared are neither directly cis or trans to each other, and this results in a 'stepped' rather than 'planar' zig-zag chain (Figure 4a).

Our previous systematic studies on the solvothermal chemistry of vanadium oxyfluorides have highlighted several general features in the structural and compositional features of the reaction products versus key synthetic variables. In particular, for the same reaction mixture an increase in reaction temperature typically results in both a reduction in the average vanadium oxidation state and an increase in the dimensionality of the vanadium oxyfluoride sublattice ${ }^{4}$. Both of these features can be seen in our preliminary exploration of the molybdenum oxyfluoride systems presented here. For example, the reactions used to prepare $\mathbf{1}$ and $\mathbf{2}$ differ significantly in the reaction temperature. Raising the temperature from $100{ }^{\circ} \mathrm{C}$ to $140{ }^{\circ} \mathrm{C}$ results in reduction of Mo from the +VI to the +IV state and also an increased degree of condensation, from corner-shared to edge-shared octahedra. Each of the three reactions carried out at higher temperatures leads to further condensation of the MoOF sublattice; to tetrameric units in $\mathbf{3}$ and $\mathbf{4}$, and to the chain moiety in $\mathbf{5}$. Reactions analogous to those used to prepare $\mathbf{3}$ and $\mathbf{4}$, if carried out at $100{ }^{\circ} \mathrm{C}$, produce the known 
monomeric compounds $\left(\mathrm{NH}_{4}\right)_{2} \mathrm{MoOF}_{5}{ }^{10}$ and $\mathrm{K}_{2} \mathrm{MoO}_{2} \mathrm{~F}_{4} \cdot \mathrm{H}_{2} \mathrm{O}^{8}$, respectively. Of course, further systematic work is required to expand on this understanding and, ultimately, be able to control both structural features and oxidation state to a finer degree. Our recent observation $^{6,7}$ of the ability of ionic liquid solvents to control both oxidation state and dimensionality in VOF systems may be of benefit in this regard.

The observation of reduced Mo in compounds $\mathbf{2}-\mathbf{5}$ is of interest, first as it gives rise to the opportunity for Mo-Mo bonding but also as it may lead to further opportunities in the preparation of a variety of electronically-active materials in these systems. Considering the metal-metal bonding first, the Mo-Mo inter-octahedral contacts shown in Table 4 are all in the range $2.52-2.55 \AA$. This compares to the Mo-Mo contact distances observed in many reduced molybdenum oxides and phosphates based on edge-sharing octahedral units ${ }^{28-30}$. When these Mo-Mo bonded arrays occur in extended chain or layer arrangements metallic behaviour often occurs, as in $\mathrm{La}_{2} \mathrm{Mo}_{2} \mathrm{O}_{7}^{29}$. However, in the case of $\mathbf{5}$ this is unlikely as the Mo-Mo distances alternate, long-short, along the chain.

Mo-Mo bonding generally results in a spin-paired $S=0$ ground state, with consequent diamagnetic behaviour. However, if some of the spins remain unpaired, then exotic magnetic behaviour may result. An exciting recent example ${ }^{31}$ occurs in the compound $\mathrm{LiZn}_{2} \mathrm{Mo}_{3} \mathrm{O}_{8}$, a mixed valence system with an average Mo oxidation state of +3.67 . Here, only six of the seven available d electrons are held in Mo-Mo bonds, and the seventh remains unpaired and delocalised over a triangular $\mathrm{Mo}_{3} \mathrm{O}_{13}$ cluster. Geometric magnetic frustration results in a possible 'resonating valence-bond' ground state.

Being able to control and exploit the variable red-ox behaviour within these MoOFs, in parallel with the occurrence or absence of Mo-Mo bonding, is therefore of potential interest to the development of new candidate low dimensional quantum magnetic systems. Another highly topical area where they may be potential for development of new MoOFbased materials is lithium battery technology. The easily accessible reduced oxidation states together with the propensity for fluorides to increase the maximum electrical redox potential $^{32}$ means that there is great scope for producing candidate cathode materials in these systems. For both these applications, the observation of simultaneous extended connectivity and reduced Mo oxidation state, observed in $\mathbf{5}$, is particularly significant.

In summary, we have shown that solvothermal synthesis, in mixed water-ethylene glycol solvents, provides a facile route to the preparation of highly fluorinated, reduced molybdenum oxyfluorides. The compounds prepared so far exhibit some novel features and provide food-for-thought in the design of more specifically targeted compositions and structure types with potentially interesting electronic properties, for example. Further work to understand and control Mo oxidation state, structural connectivity and dimensionality may pave the way for preparing novel materials with scientifically and technologically interesting electronic/electrical properties in MoOF-based systems.

Acknowledgements We thank Prof. Alex Slawin and Dr Yang Li for assistance in collecting the diffraction data, and the University of St Andrews and EPSRC for funding.

\section{*Crystal Data}

Crystallographic data for structures 1, 2 and $\mathbf{5}$ have been deposited with the Cambridge Crystallographic Data Centre as supplementary publication nos. 885588-90. Copies of the 
data can be obtained, free of charge, on application to CCDC (e-mail: deposit@ccdc.cam.ac.uk). Corresponding cif files for structures $\mathbf{3}$ and $\mathbf{4}$ have been deposited with the Inorganic Crystal Structure Database; deposition numbers 424782 and 424783 (e-mail: crysdata@ fiz-karlsruhe.de).

\section{References}

1. 'Advanced Inorganic Fluorides', eds. T. Nakajima, B. Zemva, A. Tressaud, Elsevier, Lausanne, 2000.

2. D. W. Aldous, N. F. Stephens, P. Lightfoot, Dalton Trans. (2007) 2271.

3. D. W. Aldous, R. J. Goff, J. P. Attfield, P. Lightfoot, Inorg. Chem. 46 (2007) 1277.

4. D. W. Aldous, N. F. Stephens, P. Lightfoot, Dalton Trans. (2007) 4207.

5. K. Adil, M. Leblanc, V. Maisonneuve, P. Lightfoot, Dalton Trans. 39 (2010) 5983.

6. F. Himeur, P. K. Allan, S. J. Teat, R. J. Goff, R. E. Morris, P. Lightfoot, Dalton Trans. 39 (2010) 6018.

7. F. H. Aidoudi, D. W. Aldous, R. J. Goff, A. M. Z. Slawin, J. P. Attfield, R. E. Morris, P. Lightfoot, Nature Chem. 3 (2011) 801.

8. D. Grandjean, R. Weiss, Bull. Soc. Chim. Fr. (1967) 3040.

9. P. A. Maggard, T. S. Nault, C. L. Stern, K. R. Poeppelmeier, J. Solid State Chem. 175 (2003) 27.

10. R. Mattes, K. Mennemann, N. Jaeckel, H. Rieskamp, H. J. Brockmeyer, J. Less Comm. Met. 76 (1980) 199.

11. J. Dirand, L. Ricard, R. Weiss, Trans. Met. Chem. 1 (1975) 2.

12. R. Mattes, G. Lux, Z. Anorg. Allg. Chem. 424 (1976) 173.

13. M. Liemkuehler, N. Buchholz, R. Mattes, Z. Naturforsch. 44 (1989) 389.

14. H. Lin, B. Yan, P. D. Boyle, P. A. Maggard, J. Solid State Chem. 179 (2006) 217.

15. J. L. Fourquet, H. Duroy, M. P. Crosnier-Lopez, Z. Anorg. Allg. Chem. 623 (1997) 439.

16. A. Müller, A. Ruck, M. Dartmann, U. Reinsch-Vogell, Angew. Chem. Int. Ed. Engl. 20 (1981) 483.

17. A. Michaelovski, F. Hussain, B. Spingler, J. Wagler, G. R. Patzke, Cryst. Growth Des. 9 (2009) 755.

18. J. M. Moutou, J. P. Chaminade, M. Pouchard, P. Hagenmuller, Rev. Chim. Miner. 23 (1986) 27.

19. R. Mattes, G. Müller, H. J. Becher, Z. Anorg. Allg. Chem. 389 (1972) 177.

20. R. Mattes, G. Müller, H. J. Becher, Z. Anorg. Allg. Chem. 416 (1975) 256.

21. A. Michailovski, G. R. Patzke, Chem. Eur. J. 12 (2006) 9122.

22. A. K. Stover, J. R. Gutnick, A. Narducci Sarjeant, A. J. Norquist, Inorg. Chem. 46 (2007) 4389.

23. G. M. Sheldrick, Acta Crystallogr. A64 (2008) 112.

24. N. E. Brese, M. O’Keefe, Acta Crystallogr. B47 (1991) 192

25. A. S. Wills, Valist, 2010 (program available from www.ccp14.ac.uk).

26. E. Burkholder, J. Zubieta, Inorg. Chim. Acta 357 (2004) 279.

27. N. Buchholz, R. Mattes, Angew. Chem. Int. Ed. Engl. 25 (1986) 1104.

28. A. Moini, M. A. Subramanian, A. Clearfield, F. J. DiSalvo, W. H. McCarroll, J. Solid State Chem. 66 (1987) 136.

29. C. C. Torardi, R. E. McCarley, J. Solid State Chem. 37 (1981) 393.

30. R. C. Haushalter, L. A. Mundi, Chem. Mater. 4 (1992) 31.

31. J. P. Sheckleton, J. R. Neilson, D. G. Soltan, T. M. McQueen, Nature Materials 11 (2012) 493. 
32. N. Recham, J-N. Chotard, J-C. Jumas, L. Laffont, M. Armand and J-M. Tarascon, Chem. Mater. 22 (2010) 1142. 
Table 1. Some previous examples of 'fluorine-rich' MoOF bulding units

\begin{tabular}{|c|c|c|c|}
\hline Compound Formula & Structural Unit & $\begin{array}{c}\text { Mo } \\
\text { Ox. } \\
\text { State }\end{array}$ & Ref \\
\hline $\mathrm{K}_{2}\left[\mathrm{MoOF}_{5}\right] \cdot \mathrm{H}_{2} \mathrm{O}$ & Monomer & $\mathrm{V}$ & 8 \\
\hline $\mathrm{K}_{2}\left[\mathrm{MoO}_{2} \mathrm{~F}_{4}\right] \cdot \mathrm{H}_{2} \mathrm{O}$ & cis-monomer & VI & 8 \\
\hline $\mathrm{Ag}_{3}\left[\mathrm{MoO}_{3} \mathrm{~F}_{3}\right]\left(\mathrm{Ag}_{3} \mathrm{MoO}_{4}\right)$ & fac-monomer & VI & 9 \\
\hline $\mathrm{Cs}_{3}\left[\mathrm{Mo}_{2} \mathrm{O}_{6} \mathrm{~F}_{3}\right]$ & Face-sharing dimer (F-bridge) & VI & 10 \\
\hline$\left[\mathrm{MoO}\left(\mathrm{S}_{2} \mathrm{CNEt}_{2}\right)_{3}\right]_{2}\left[\mathrm{Mo}_{2} \mathrm{O}_{4} \mathrm{~F}_{6}\right]$ & Edge-sharing dimer (F-bridge) & VI & 11 \\
\hline$\left(\mathrm{NH}_{4}\right)_{2}\left[\mathrm{Mo}_{2} \mathrm{O}_{4} \mathrm{~F}_{4}\left(\mathrm{H}_{2} \mathrm{O}\right)_{2}\right]$ & Edge-sharing dimer (O-bridge) & $\mathrm{V}$ & 12 \\
\hline$\left(\mathrm{NH}_{4}\right)_{3}\left[\mathrm{Mo}_{2} \mathrm{O}_{2} \mathrm{~F}_{9}\right]$ & Corner-sharing dimer (F-bridge) & $\mathrm{V}$ & 10 \\
\hline $\mathrm{K}_{2}\left(\mathrm{NMe}_{4}\right)\left[\mathrm{Mo}_{2} \mathrm{O}_{2} \mathrm{~F}_{8}\left(\mathrm{H}_{2} \mathrm{O}\right)\right]$ & Corner-sharing dimer (F-bridge) & $\mathrm{V}$ & 13 \\
\hline$\left(\mathrm{C}_{4} \mathrm{H}_{4} \mathrm{~N}_{2}\right)_{3} \mathrm{Ag}_{3}\left[\mathrm{Mo}_{2} \mathrm{O}_{4} \mathrm{~F}_{7}\right]$ & Corner-sharing dimer (F-bridge) & VI & 14 \\
\hline $\mathrm{Ba}_{4}\left[\mathrm{Mo}_{2} \mathrm{O}_{5} \mathrm{~F}_{6}\right] \mathrm{F}\left(\mathrm{HF}_{2}\right)_{3}$ & Corner-sharing dimer (O-bridge) & VI & 15 \\
\hline $\mathrm{K}\left(\mathrm{NMe}_{4}\right)_{2}\left[\mathrm{Mo}_{3} \mathrm{O}_{6} \mathrm{~F}_{9}\right]$ & Corner-sharing trimer (X-bridge) & VI & 13 \\
\hline$\left(\mathrm{NH}_{4}\right)_{5}\left[\mathrm{Mo}_{3} \mathrm{O}_{4} \mathrm{~F}_{9}\right]$ & Edge-sharing trimer (O-bridge) & IV & 16 \\
\hline$\left(\mathrm{C}_{8} \mathrm{H}_{16} \mathrm{~N}\right)_{2} \mathrm{Na}_{4}\left[\mathrm{Mo}_{6} \mathrm{O}_{18} \mathrm{~F}_{6}\right] \cdot 6 \mathrm{H}_{2} \mathrm{O}$ & Planar edge-sharing hexamer & VI & 17 \\
\hline $\mathrm{NaMoO}_{3} \mathrm{~F}$ & cis-Edge-sharing chain (O-bridge) & VI & 18 \\
\hline $\mathrm{CsMoO}_{2} \mathrm{~F}_{3}$ & $\begin{array}{l}\text { cis-Corner-sharing chain (F- } \\
\text { bridge) }\end{array}$ & VI & 19 \\
\hline$\left(\mathrm{NH}_{4}\right)_{2} \mathrm{MoO}_{3} \mathrm{~F}_{2}$ & $\begin{array}{l}\text { trans-Corner-sharing chain (O- } \\
\text { bridge) }\end{array}$ & VI & 20 \\
\hline
\end{tabular}

Table 2. Synthetic conditions and analytical data. Each reaction composed $0.144 \mathrm{~g}$ (1 mmol) $\mathrm{MoO}_{3}$ and $0.5 \mathrm{ml} \mathrm{HF}(48 \%$, aq) together with the components below. Reaction duration was 24 hours in each case.

\begin{tabular}{|c|c|c|c|c|c|c|c|}
\hline Compound & $\begin{array}{c}\mathrm{H}_{2} \mathrm{O} \\
(\mathrm{ml})\end{array}$ & $\begin{array}{c}\mathrm{EG} \\
(\mathrm{ml})\end{array}$ & \multicolumn{2}{|c|}{ 'template' } & $\mathrm{T}\left({ }^{\circ} \mathrm{C}\right)$ & $\begin{array}{c}\mathrm{CHN}(\%) \\
\text { (expected) }\end{array}$ & $\begin{array}{c}\mathrm{CHN}(\%) \\
(\text { found) }\end{array}$ \\
\hline 1 & 1 & 5 & en & $0.5 \mathrm{ml}$ & 100 & $\begin{array}{c}9.42,3.95, \\
10.98\end{array}$ & $\begin{array}{c}9.58,3.13, \\
11.05\end{array}$ \\
\hline 2 & 5 & 5 & en & $0.5 \mathrm{ml}$ & 140 & $\begin{array}{c}15.14, \\
4.66, \\
11.77\end{array}$ & $\begin{array}{c}13.62, \\
4.45, \\
\end{array}$ \\
& 1 & 5 & $\begin{array}{c}\mathrm{NH}_{4} \mathrm{OH} \\
(30 \%)\end{array}$ & 11.76 \\
\hline 3 & & & & & 160 & $0,2.99$, & $0,2.80$, \\
& & 5 & $\mathrm{KNO}_{3}$ & $0.30 \mathrm{~g}$ & 160 & - & - \\
\hline 4 & 2 & 5 & pip & $0.258 \mathrm{~g}$ & 190 & 11.28, & 11.93, \\
\hline 5 & 1 & & & & & $2.84,6.58$ & $2.79,6.43$ \\
\hline
\end{tabular}

Abbreviations: $\mathrm{EG}=$ ethylene glycol; en = ethylene diammine; pip = piperazine . 
Table 3. Crystallographic parameters for compounds 1-5

\begin{tabular}{|c|c|c|c|c|c|}
\hline Compound & 1 & 2 & 3 & 4 & 5 \\
\hline Formula & $\mathrm{Mo}_{2} \mathrm{O}_{5} \mathrm{~F}_{6} \mathrm{C}_{4} \mathrm{H}_{20} \mathrm{~N}_{4}$ & $\mathrm{Mo}_{2} \mathrm{O}_{6} \mathrm{~F}_{2} \mathrm{C}_{6} \mathrm{H}_{22} \mathrm{~N}_{4}$ & $\mathrm{Mo}_{4} \mathrm{O}_{8} \mathrm{~F}_{10} \mathrm{H}_{24} \mathrm{~N}_{6}$ & $\mathrm{Mo}_{4} \mathrm{O}_{8} \mathrm{~F}_{10} \mathrm{~K}$ & $\mathrm{MoOF}_{3} \mathrm{C}_{2} \mathrm{H}_{6} \mathrm{~N}$ \\
\hline Space Group & $\mathrm{C} 2 / \mathrm{c}$ & $\mathrm{C} 2 / \mathrm{c}$ & Pmnn & Pmnn & $\mathrm{C} 2 / \mathrm{c}$ \\
\hline $\mathrm{a}[\AA]$ & $17.686(3)$ & $21.006(3)$ & $6.309(1)$ & $6.0483(7)$ & 15.616(9) \\
\hline $\mathrm{b}[\AA]$ & $6.3262(9)$ & $6.0562(7)$ & $9.457(2)$ & $9.351(1)$ & $8.355(5)$ \\
\hline c $[\AA]$ & $13.510(2)$ & $11.272(1)$ & $14.957(3)$ & $14.487(2)$ & $9.517(6)$ \\
\hline$\beta\left[^{\circ}\right]$ & $108.485(4)$ & $97.324(4)$ & & & \\
\hline $\mathrm{V}\left[\AA^{3}\right]$ & $1433.6(4)$ & $1422.3(3)$ & $892.4(3)$ & $819.4(2)$ & $118.467(7)$ \\
\hline $\mathrm{Z}$ & 4 & 4 & 2 & 2 & 8 \\
\hline$\rho_{\text {calc }}\left[\mathrm{g} \mathrm{cm}^{-3}\right]$ & 2.364 & 2.252 & 2.924 & 3.795 & 2.592 \\
\hline$\mu\left[\mathrm{mm}^{-1}\right]$ & 1.844 & 1.827 & 2.889 & 4.656 & 2.370 \\
\hline $\begin{array}{c}\text { Crystal Size } \\
{[\mathrm{mm}]}\end{array}$ & $0.2 \times 0.2 \times 0.2$ & $0.22 \times 0.15 \times 0.08$ & $\begin{array}{l}0.10 \times 0.03 \times \\
0.03\end{array}$ & $\begin{array}{l}0.10 \times 0.10 \times \\
0.03\end{array}$ & $\begin{array}{l}0.19 \times 0.17 \times \\
0.15\end{array}$ \\
\hline $\mathrm{F}(000)$ & 1000 & 952 & 728 & 872 & 816 \\
\hline Reflns Collected & 4566 & 7260 & 5428 & 4889 & 6598 \\
\hline $\begin{array}{l}\text { Independent } \\
\text { Reflns }\end{array}$ & 1775 & 1693 & 898 & 1030 & 1925 \\
\hline $\mathrm{R}_{\text {int }}$ & 0.023 & 0.113 & 0.022 & 0.027 & 0.023 \\
\hline $\begin{array}{c}\text { Obsd Data } \\
{[\mathrm{I}>2 \sigma(\mathrm{I})]}\end{array}$ & 1304 & 1248 & 868 & 896 & 1656 \\
\hline Data/ Parameters & $1775 / 96$ & $1693 / 95$ & $898 / 76$ & $1030 / 76$ & $1925 / 73$ \\
\hline GOF on $F^{2}$ & 1.13 & 1.23 & 1.25 & 1.26 & 1.11 \\
\hline $\begin{array}{c}\mathrm{R} 1, w R 2[\mathrm{I}>2 \\
\sigma(\mathrm{I})]\end{array}$ & $0.0247,0.0608$ & $0.0985,0.1436$ & $0.0320,0.0810$ & $0.0419,0.0840$ & $0.0285,0.0663$ \\
\hline $\begin{array}{c}\mathrm{R} 1, w R 2 \text { (all } \\
\text { data) }\end{array}$ & $0.0281,0.0635$ & $0.1393,0.1517$ & $0.0333,0.0819$ & $0.0456,0.0852$ & $0.0321,0.0682$ \\
\hline
\end{tabular}

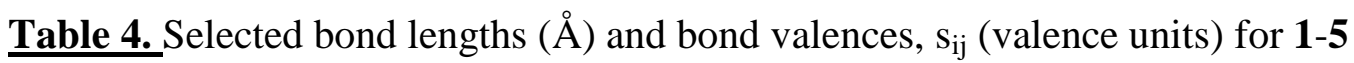

\begin{tabular}{|c|c|c|}
\hline \multicolumn{3}{|c|}{ 1: $\left[\mathrm{C}_{2} \mathrm{H}_{10} \mathrm{~N}_{2}\right]_{2}\left[\mathrm{Mo}_{2} \mathrm{O}_{5} \mathrm{~F}_{6}\right]$} \\
\hline Bond & Bond Length $(\AA)$ & $s_{i j}$ \\
\hline Mo1-O1 & $1.707(2)$ & 1.720 \\
\hline Mo1-O2 & $1.702(2)$ & 1.743 \\
\hline Mo1-O3 & $1.901(1)$ & 1.009 \\
\hline Mo1-F1 & $2.084(2)$ & 0.474 \\
\hline Mo1-F1 & $2.007(2)$ & 0.584 \\
\hline Mo1-F2 & $2.151(2)$ & 0.396 \\
\hline & & $\sum$ Mo1 $=5.94$ \\
\hline
\end{tabular}




\begin{tabular}{|c|c|c|}
\hline \multicolumn{3}{|c|}{ 2: $\left[\mathrm{Mo}_{2} \mathrm{O}_{4} \mathrm{~F}_{2}\left(\mathrm{C}_{2} \mathrm{H}_{8} \mathrm{~N}_{2}\right)_{2}\right] \cdot \mathrm{C}_{2} \mathrm{H}_{6} \mathrm{O}_{2}$} \\
\hline Bond & Bond Length $(\AA)$ & $s_{i j}$ \\
\hline Mo1-01 & $1.877(6)$ & 1.086 \\
\hline Mo1-O1' & $1.934(6)$ & 0.931 \\
\hline Mo1-F1/O2* & $1.842(5)$ & $0.46 / 0.60$ \\
\hline Mo1-F2/O3* & $1.885(5)$ & $0.41 / 0.53$ \\
\hline Mo1-N1 & $2.227(7)$ & 0.555 \\
\hline Mo1-N2 & $2.149(6)$ & 0.685 \\
\hline & & $\sum$ Mo1 $=5.25$ \\
\hline Mo1-Mo1 & $2.522(2)$ & \\
\hline
\end{tabular}

\begin{tabular}{|c|c|c|}
\hline \multicolumn{3}{|c|}{ 3: $\left(\mathrm{NH}_{4}\right)_{6}\left[\mathrm{Mo}_{4} \mathrm{O}_{8} \mathrm{~F}_{10}\right]$} \\
\hline Bond & Bond Length $(\AA)$ & $s_{i j}$ \\
\hline Mo1-O1 & $1.690(5)$ & 1.801 \\
\hline Mo1-O3 & $1.948(4)$ & 0.897 \\
\hline Mo1-O3' & $1.948(4)$ & 0.897 \\
\hline Mo1-F1 & $2.040(3)$ & 0.534 \\
\hline Mo1-F1' & $2.040(3)$ & 0.534 \\
\hline Mo1-F3 & $2.152(4)$ & 0.395 \\
\hline & & $\sum$ Mo1 $=5.06$ \\
\hline Mo2-O2 & $1.674(5)$ & 1.881 \\
\hline Mo2-O3 & $1.950(4)$ & 0.892 \\
\hline Mo2-O3' & $1.950(4)$ & 0.892 \\
\hline Mo2-F2 & $2.049(3)$ & 0.521 \\
\hline Mo2-F2' & $2.049(3)$ & 0.521 \\
\hline Mo2-F3 & $2.173(4)$ & 0.373 \\
\hline & & $\sum$ Mo2 = 5.08 \\
\hline Mo1-Mo2 & $\mathbf{2 . 5 5 2 ( 1 )}$ & \\
\hline
\end{tabular}

\begin{tabular}{|c|c|c|}
\hline \multicolumn{3}{|c|}{ 4: $\mathrm{K}_{6}\left[\mathrm{Mo}_{4} \mathrm{O}_{8} \mathrm{~F}_{10}\right]$} \\
\hline Bond & Bond Length $(\AA)$ & $s_{i j}$ \\
\hline Mo1-O1 & $1.689(6)$ & 1.806 \\
\hline Mo1-O3 & $1.938(4)$ & 0.921 \\
\hline Mo1-O3' & $1.938(4)$ & 0.921 \\
\hline Mo1-F1 & $2.016(3)$ & 0.570 \\
\hline Mo1-F1' & $2.016(3)$ & 0.570 \\
\hline
\end{tabular}




\begin{tabular}{|c|c|c|}
\hline Mo1-F3 & $2.153(5)$ & 0.394 \\
\hline & & $\sum \mathrm{Mo1}=\mathbf{5 . 1 8}$ \\
\hline Mo2-O2 & $1.679(6)$ & 1.855 \\
\hline Mo2-O3 & $1.948(4)$ & 0.897 \\
\hline Mo2-O3' & $1.948(4)$ & 0.897 \\
\hline Mo2-F2 & $2.041(3)$ & 0.533 \\
\hline Mo2-F2' & $2.041(3)$ & 0.533 \\
\hline Mo2-F3 & $2.156(4)$ & 0.390 \\
\hline & & $\sum M o 2=\mathbf{5 . 1 1}$ \\
\hline Mo1-Mo2 & $\mathbf{2 . 5 4 2 ( 1 )}$ & \\
\hline
\end{tabular}

\begin{tabular}{|c|c|c|}
\hline \multicolumn{3}{|c|}{ 5: $\left[\mathrm{C}_{4} \mathrm{H}_{12} \mathrm{~N}_{2}\right]_{0.5}\left[\mathrm{MoOF}_{3}\right]$} \\
\hline Bond & Bond Length $(\AA)$ & $s_{i j}$ \\
\hline Mo1-O1 & $1.685(2)$ & 1.825 \\
\hline Mo1-F1 & $2.118(2)$ & 0.433 \\
\hline Mo1-F2 & $2.174(2)$ & 0.372 \\
\hline Mo1-F2' & $2.214(2)$ & 0.334 \\
\hline Mo1-F3 & $1.973(2)$ & 0.640 \\
\hline Mo1-F3' & $2.043(2)$ & 0.530 \\
\hline & & $\sum$ Mo1 $=\mathbf{4 . 1 3}$ \\
\hline Mo1-Mo1 & $\mathbf{2 . 5 4 4 ( 2 )}$ & \\
\hline
\end{tabular}




\section{Figures}

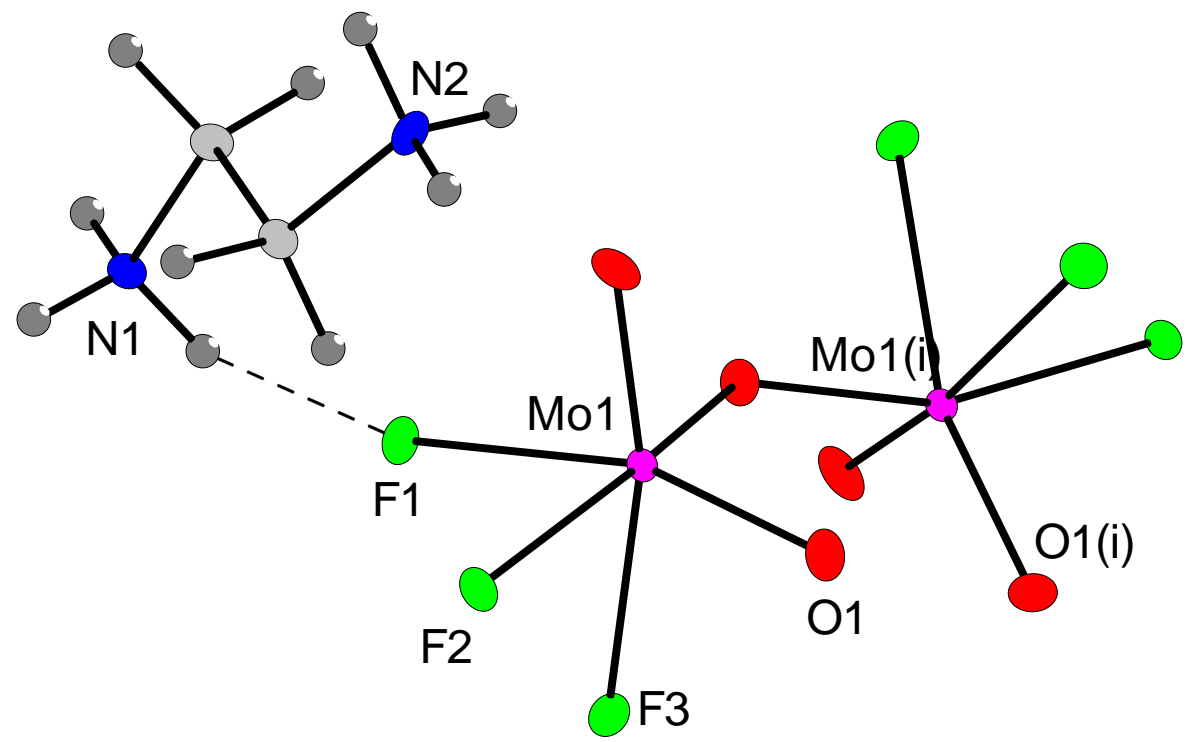

Figure 1 Building unit in $\mathbf{1}$. Atoms drawn as 50\% probability ellipsoids. Symmetry operator: (i) $1-\mathrm{x}, \mathrm{y}, 1 / 2-\mathrm{z}$.
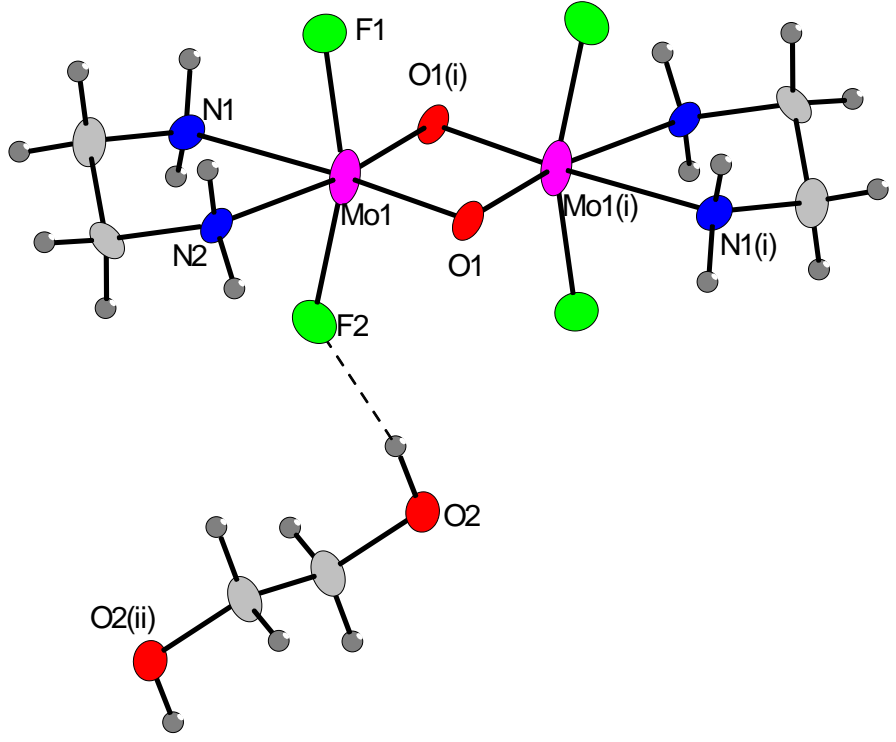

Figure 2 Building unit in 2. Symmetry operator: (i) $1 / 2-x, 1 / 2-y, 1-z$. 


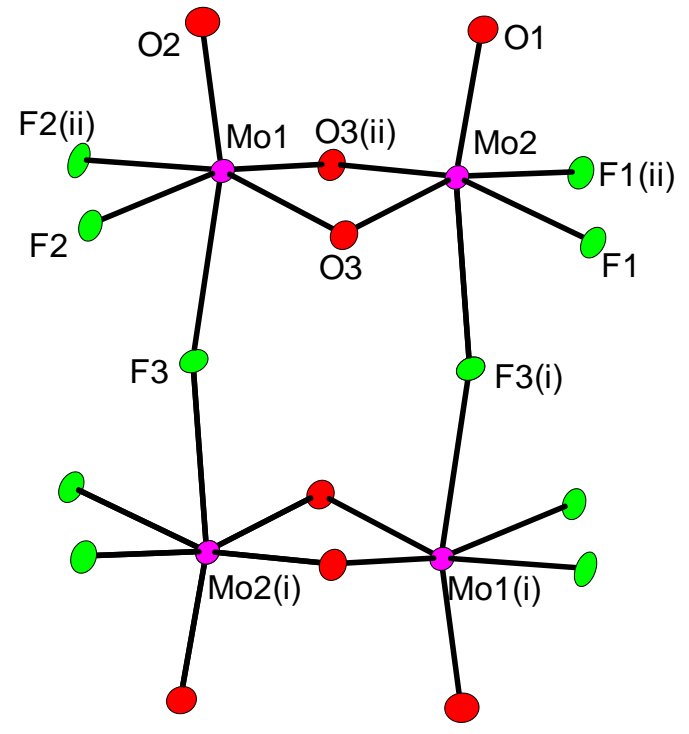

Figure 3a Tetramer unit in 3 and 4. Symmetry operators: (i) $x,-y,-z$ (ii) $-x, y, z$. 


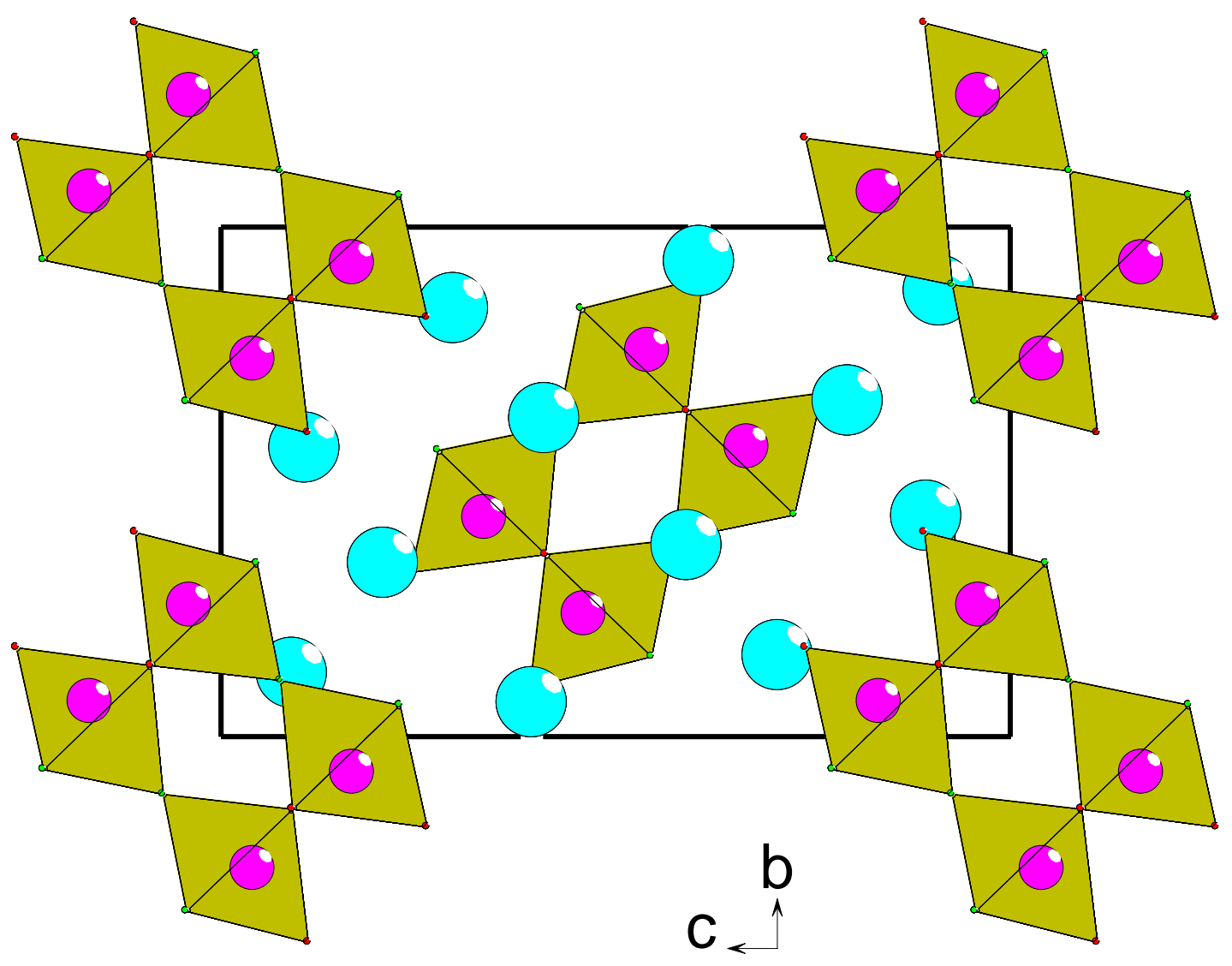

Figure 3b Packing of tetrameric units in $\mathbf{3}$ and $\mathbf{4}$, along the $a$-axis. 


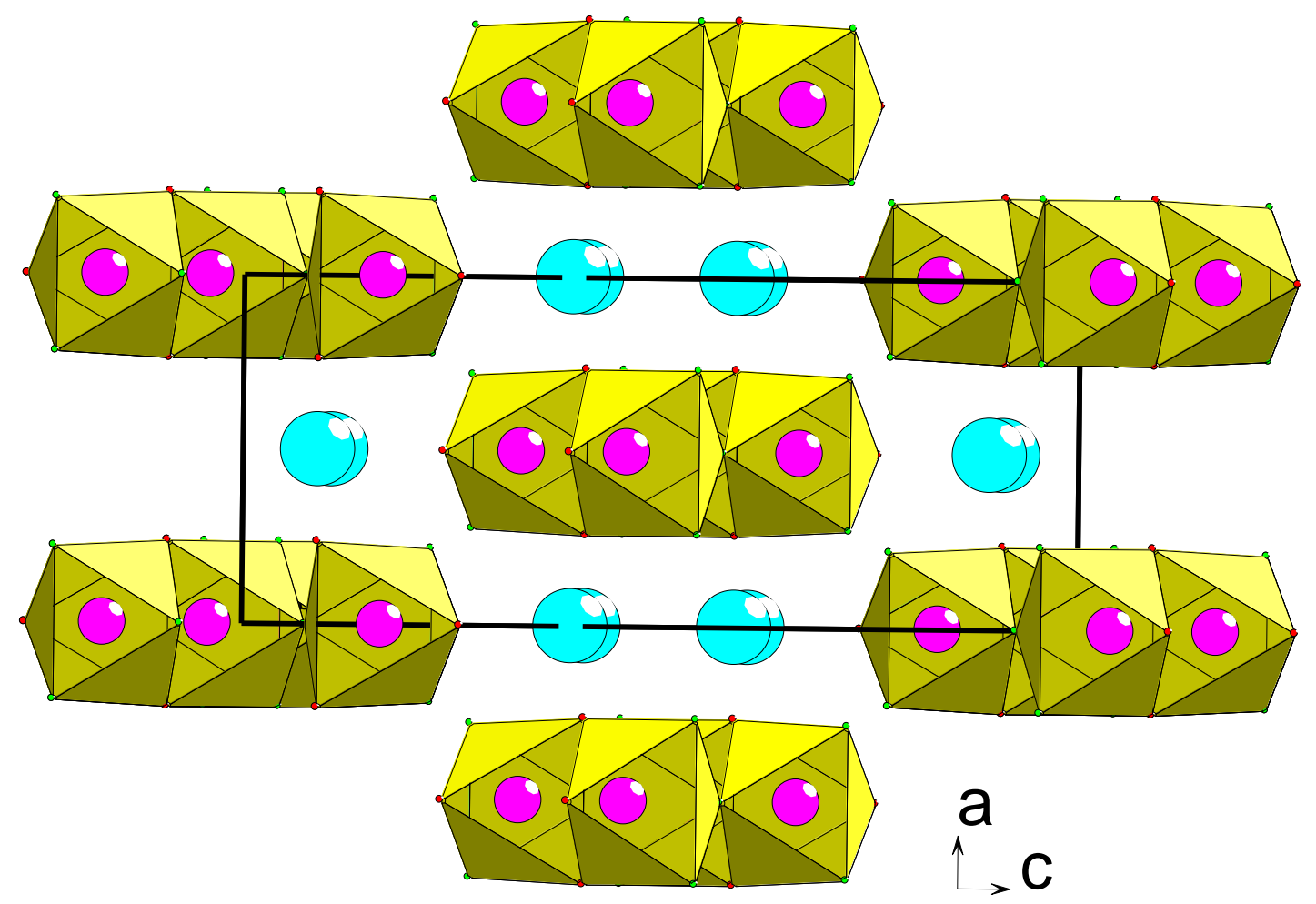

Figure 3c Packing of tetrameric units in $\mathbf{3}$ and $\mathbf{4}$, along the $b$-axis.

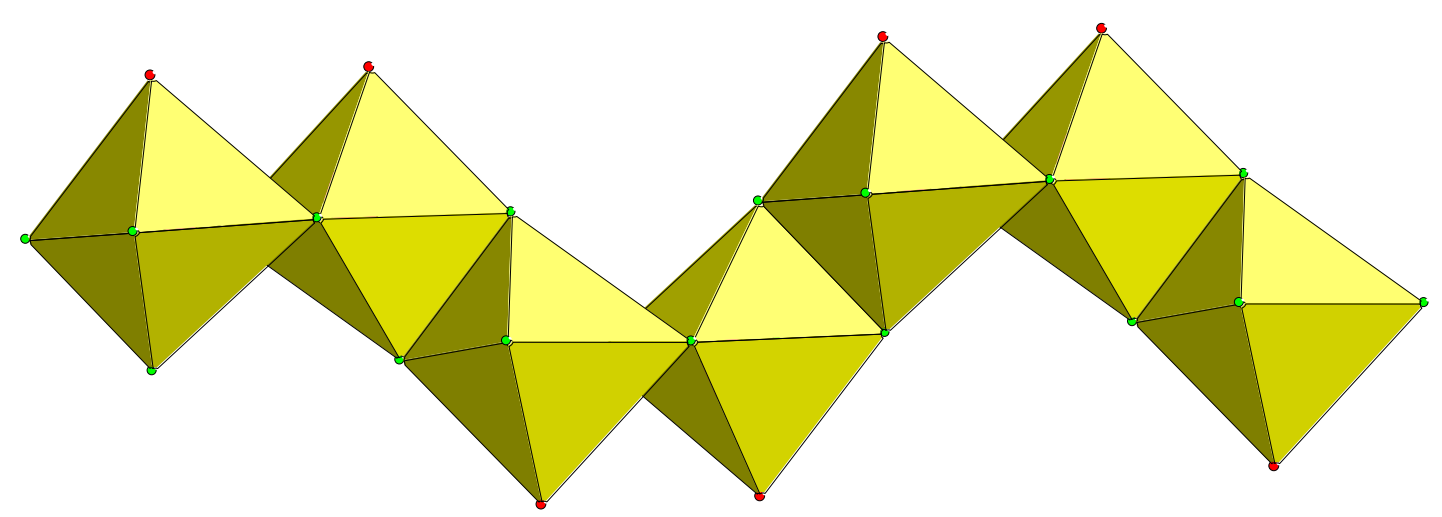




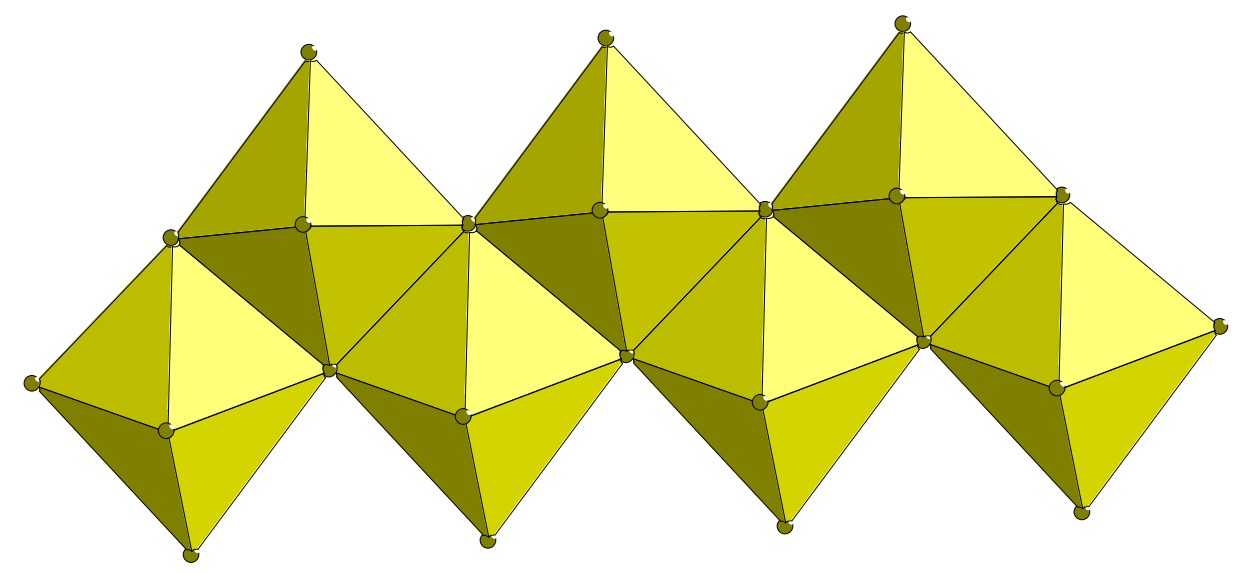

Figure 4a 'Stepped zig-zag' $\left[\mathrm{MoOF}_{3}\right]_{\mathrm{n}}$ edge-sharing octahedral chain motif in $\mathbf{5}$ (above) compared to the 'planar zig-zag' $\left[\mathrm{MoO}_{3} \mathrm{~F}\right]_{\mathrm{n}}$ chain in $\mathrm{NaMoO}_{3} \mathrm{~F}$.

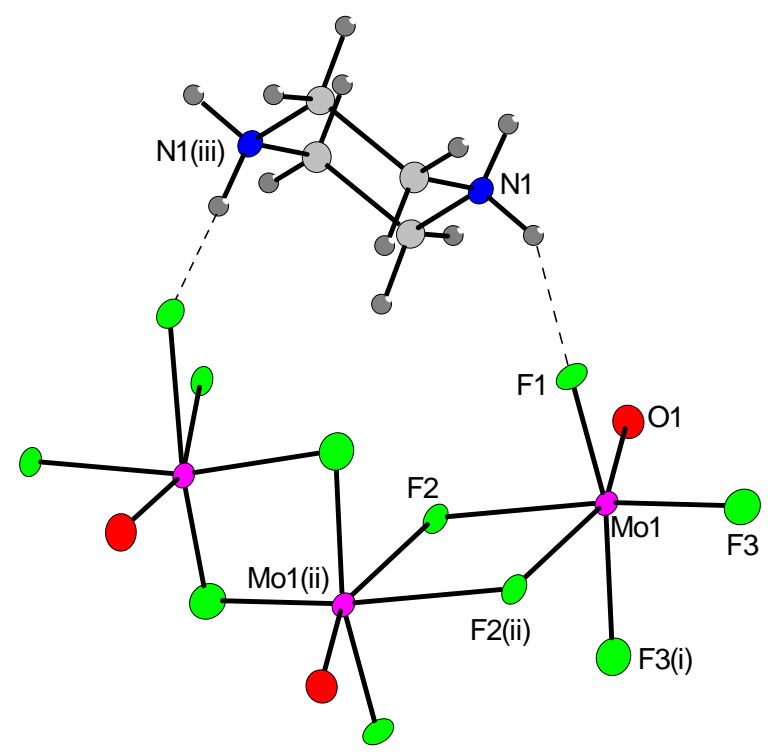

Figure 4b Building unit in 5. Symmetry operators: (i) $1-\mathrm{x}, \mathrm{y}, 1 / 2-\mathrm{z}$ (ii) $1-\mathrm{x}, 1-\mathrm{y},-\mathrm{z}$ (iii) $1 / 2-\mathrm{x}, 3 / 2-\mathrm{y},-1-\mathrm{z}$. 


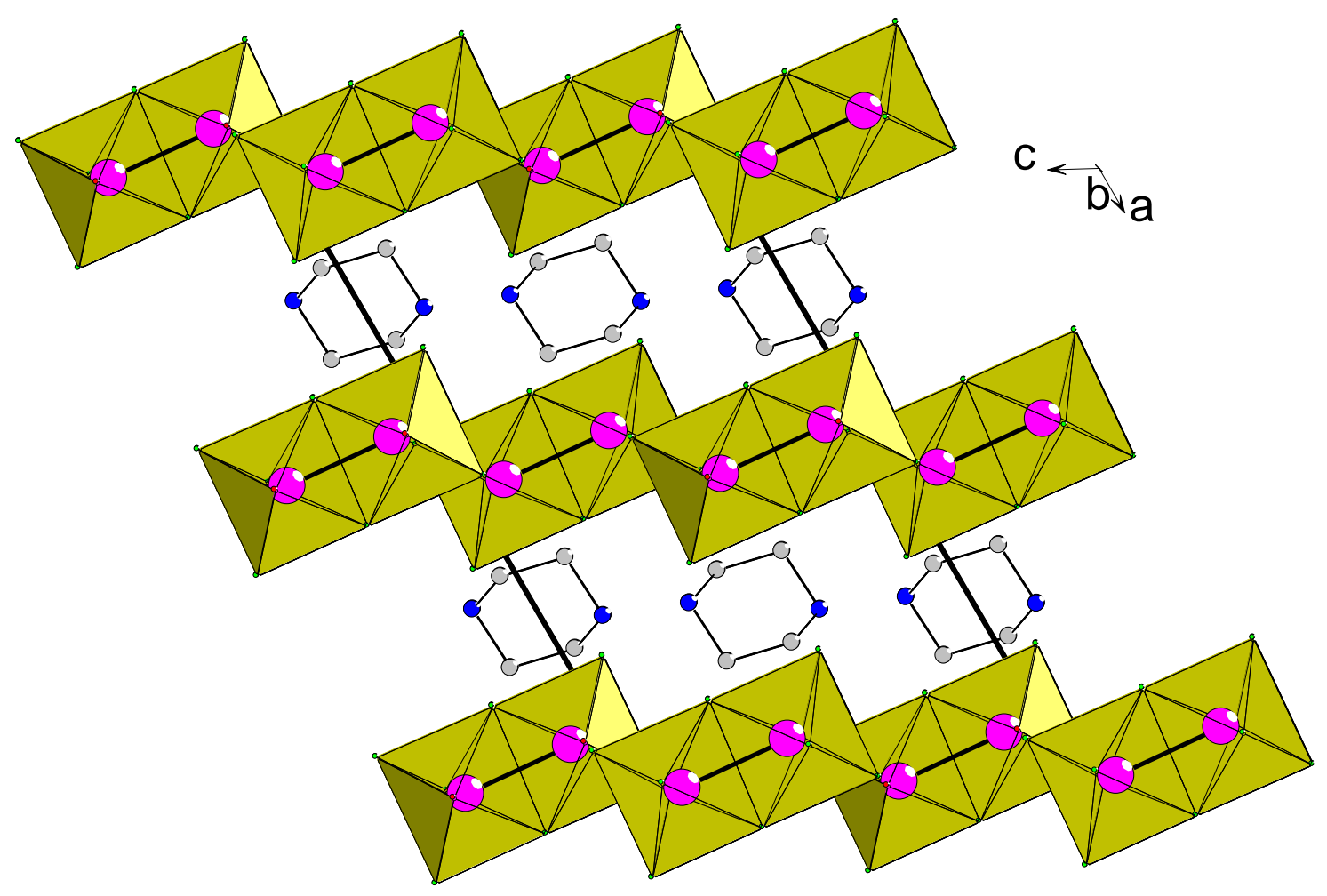

Figure 4c Unit cell packing in 5, with Mo-Mo bonds highlighted. H atoms are not shown. 


\section{Graphical Abstract:}

Solvothermal synthesis provides a facile route to reduced molybdenum oxyfluorides containing novel metal-metal bonded units.

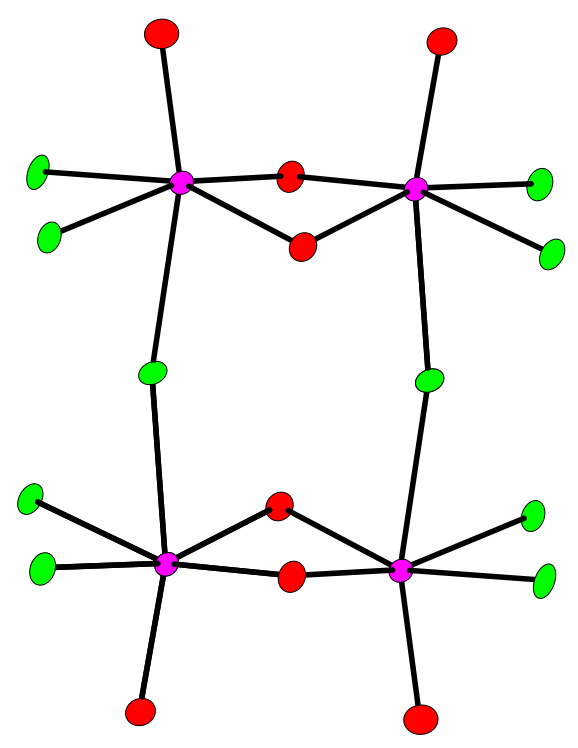

